\title{
GASTRIC ANTIULCER AND ULCER HEALING EFFECTS OF PUNICA GRANATUM L. PEEL EXTRACT IN RATS: ROLE OF OFFENSIVE AND DEFENSIVE MUCOSAL FACTORS AND OXIDATIVE STRESS
}

\author{
INDAL CHAUHAN, ANKITA SHARMA, MAYANK GANGWAR, MANISH KUMAR GAUTAM, AMIT SINGH, \\ RAJ KUMAR GOEL*
}

Department of Pharmacology, Faculty of Medicine, Institute of Medical Sciences, Banaras Hindu University, Varanasi 221005, India Email: rkgoelbhu50@gmail.com

Received: 10 Nov 2015 Revised and Accepted: 09 Mar 2017

\section{ABSTRACT}

Objective: The present work incorporates the study of gastric antiulcer and ulcer healing effects of dried Punica granatum (PG) peel 50\% ethanol extract (PGE) in rats.

Methods: PGE (100 mg/kg) was administered orally once daily to rats either before or after induction of gastric ulcers (GU) for $7 \mathrm{~d}$. Antiulcer effects of PGE were seen against acute GU, induced by pylorus ligation (PL), cold restraint stress (CRS), aspirin and ethanol while, ulcer healing in acetic acid (AA)-induced chronic GU in rats. Ulcer index (UI), gastric juice volume, acid-pepsin and mucin secretions and gastric mucosal glycoproteins, free radicals (LPO and NO) and antioxidants (SOD and GSH) were estimated.

Results: PGE showed a decrease in UI in all GU models ( 45.6 to $79.7 \%, \mathrm{P}<0.05$ to $\mathrm{P}<0.001$ ) indicating both protective and healing effects. PGE showed little or no effects on volume, acid-pepsin concentration and output but increased mucin secretion $(55.1 \%, \mathrm{P}<0.05)$ and mucosal glycoproteins $(35.7 \%$, $\mathrm{P}<0.05)$ in PL rats. CRS rats showed an increase in LPO and NO (48.4 to 58.3\%, P<0.01) and SOD $(21.8 \%, \mathrm{P}<0.01)$ but decrease in GSH and CAT $(33.1$ to $44.8 \%, \mathrm{P}<0.01$ to $\mathrm{P}<0.001)$ compared with unstressed rats. $\mathrm{PGE}$-treated CRS rats showed a decrease in LPO and NO (44.1 to 61.2 , $\mathrm{P}<0.01$ to $\mathrm{P}<0.001)$ and SOD (13.2\%, $\mathrm{P}<0.01$ ) and increase in GSH and CAT ( 43.8 to $48.7 \%, \mathrm{P}<0.01$ to $\mathrm{P}<0.001$ ) compared with CRS rats.

Conclusion: PGE seemed to have ulcer cytoprotective effects due to enhanced mucosal resistance and reduction in oxidative mucosal damage possibly via high antioxidant activity.

Keywords: Punica granatum peel, Gastric ulcer, Mucosal defence, Free radicals, Antioxidants

(C) 2017 The Authors. Published by Innovare Academic Sciences Pvt Ltd. This is an open access article under the CC BY license (http://creativecommons.org/licenses/by/4.0/] DOI: http://dx.doi.org/10.22159/ijpps.2017v9i5.9851

\section{INTRODUCTION}

Gastroduodenal ulceration is defects in the gastrointestinal mucosa that may extend through the muscularis mucosa. Peptic ulcer disease occurs as a result of an imbalance between offensive (acid, pepsin, bile, oxidative stress, etc.) and defensive (mucus and bicarbonate secretion, prostaglandins, blood flow, antioxidant status and the processes of restitution and regeneration after cellular injury) factors in the gastroduodenal mucosa [1]. H. pylori infection, NSAIDs, and acid secretory abnormalities are the major factors that disrupt this equilibrium. Although the acid peptic injury is necessary for ulcers to form, acid secretion is normal in almost all the patients with gastric ulcers and increased in only one-third of patients with duodenal ulcers indicating the role played by defence mechanisms in preventing ulceration. A defect in bicarbonate production and in turn, acid neutralization in the duodenal bulb, is also seen in patients with duodenal ulcer disease. A small percentage of ulcers are related to H. pylori infection or NSAID use.

However, a large number of ulcers is classified as idiopathic and may be related to defective mucosal defence mechanisms, tobacco use, genetics, rapid gastric emptying, or psychological stress [2]. Gastric lesions thus, are resultant of mucosal damage produced by a number of factors and are associated with the cellular influx, free radical generation, cytokines and growth factors [3]. The term 'cytoprotection' was coined by Andre Robert in 1979 which referred to the protection afforded by prostaglandins against experimentally induced acute gastric lesions, in doses which do not affect gastric secretion in rats [4]. Several mechanisms of gastric cytoprotection have been proposed like increased mucus and bicarbonate secretion, strengthening of the gastric mucosal barrier, increased gastric mucosal blood flow, decreased gastric motility, increased the formation of prostaglandins and sulfhydryl, scavenging of free radicals, stimulation of cellular growth and repair, decreased the release of leukotrienes, etc. [5].

Punica granatum L. (family-Punicaceae, PG) is a shrub or small tree, native to Iran, Afghanistan, Baluchistan, Mediterranean regions and Himalayas in Northern India. Furthermore, the dried pericarp and the juice of the fruit are considered beneficial for the treatment of colic, colitis, menorrhagia, oxyuriasis, headache, diuretic, acne, piles, allergic dermatitis, and treatment of oral diseases [6]. Besides the nutritional value of its fruit, different parts of this plant are reported to possess medicinal properties such as antioxidant, anti-diarrheal, anti-inflammatory, anti-cancer, antibacterial, anti-fertility, angiogenesis, apoptotic, anti-ulcer and wound healing activity [7].

Recently many workers have reported gastric ulcer protective effects of PG peel, rind and seeds against ethanol and NSAIDsinduced gastric ulcers in rats. They reported that the ulcer protective effects could be due to decreased acid secretion and promotion of mucin secretion and adhered mucin and status of mucosal antioxidants [8-11]. However, Lai and associates have reported pomegranate tannins having significant ulcer protective effects not related to any decrease in acid-pepsin secretion but due to the enhancement of mucosal defensive factors [12]. PG fruit has been reported to contain many bioactive principles mainly flavonoids, alkaloids, tannins, triterpenes and phytosterols having potential cytoprotective, anti-inflammatory, analgesic and antioxidant properties [13].

As there were conflicting reports regarding the role of offensive acid-pepsin in ulcer protective effects of PG peel, so the present study was carried out to do detailed study of the gastric antiulcer and healing effects of $50 \%$ ethanol extract of PG fruit peel (PGE) in both the acute and chronic gastric ulcers (GU) models in rats. 
Furthermore, estimation of offensive acid-pepsin secretion and free radicals and defensive, free (mucin) and adherent mucous (glycoproteins) and status of antioxidants in gastric mucosa were carried out to study the role of offensive and defensive factors and oxidative stress in its ulcer protective and healing effects.

\section{MATERIALS AND METHODS}

\section{Collection of fruits and extraction}

Fruit of PG was collected in the months of September-November from Ayurvedic Gardens, Banaras Hindu University. Peel of PG fruit was removed and dried in the shade and blended to form a fine powder. PGE was prepared by adding $200 \mathrm{~g}$ of dried fine powder of $P G$ in $1000 \mathrm{ml}$ of ethanol $(500 \mathrm{ml})$ and distilled water $(500 \mathrm{ml})$ mixture. The mixture was shaken at intervals and the extract so obtained was filtered after an interval of two days. The procedure was repeated twice at an interval of two days. PGE so obtained each time was mixed and later dried at $40^{\circ} \mathrm{C}$ in an incubator. The yield was about $20.1 \%(\mathrm{w} / \mathrm{w})$. PGE was stored at $-20^{\circ} \mathrm{C}$ until further use.

\section{Animals}

Inbred Charles-Foster (CF) albino rats (150-250 g) of either sex were obtained from the central animal house of Institute of Medical Sciences, Banaras Hindu University, Varanasi. They were kept in the departmental animal house at an ambient temperature of $26 \pm 2{ }^{\circ} \mathrm{C}$ and relative humidity 44-56\%, with light and dark cycles of 10 and $14 \mathrm{~h}$ respectively for $1 \mathrm{w}$ before and during the experiments. Animals were provided with standard rodent pellet diet (Pashu Aahar, Ramnagar, Varanasi) and the food was withdrawn 18-24 h before the experiment though the water was allowed ad libitum. 'Principles of laboratory animal care' (NIH publication no. 82-23, revised 1985) guidelines were followed. Approval from the Institutional Animal Ethical Committee was taken prior to the experimental work (Notification no.: Dean/13-14/CAEC/333 dated 20.11.2013).

\section{Drugs and chemicals}

Omeprazole (OMZ, $2.0 \mathrm{mg} / \mathrm{kg}$, Merck India Ltd., Mumbai, India), aspirin (ASP, $200 \mathrm{mg} / \mathrm{kg}$, Merck India Ltd., Mumbai, India), sucralfate (SCF, $500 \mathrm{mg} / \mathrm{kg}$ ) and all other chemicals and reagents were used of analytical grade.

\section{Gastric ulcer and offensive and defensive mucosal factors study}

PGE and the standard anti-ulcer drugs, OMZ (antisecretory) and SCF (ulcer healing) were suspended in $0.5 \%$ carboxymethylcellulose (CMC) and given orally once daily for $7 \mathrm{~d}$. The experiments were conducted on day 7, one hour after the last dose of the drugs to $18 \mathrm{~h}$ fasted rats while control rats received CMC only. The animals received $\mathrm{PGE} / \mathrm{OMZ} / \mathrm{SCF}$, orally with the help of an orogastric tube in the volume of $10 \mathrm{ml} / \mathrm{kg}$ body weight.

\section{Anti-ulcer study}

Acute GU like $2 \mathrm{~h}$ cold-restraint stress (CRS), $4 \mathrm{~h}$ pylorus ligated (PL), aspirin (ASP, $200 \mathrm{mg} / \mathrm{kg}$, oral, $4 \mathrm{~h}$ ) and ethanol (EtOH, $1 \mathrm{ml} / 200 \mathrm{~g}$ body weight, oral, $1 \mathrm{~h}$ ) were produced following the methods as reported earlier [14]. Briefly, CRS was given by strapping the rats on a wooden plank and keeping them for $2 \mathrm{~h}$ at $4-6^{\circ} \mathrm{C} .4 \mathrm{hr}$ PL was done in pentobarbitone (35 mg/kg, intraperitoneal) anaesthetized rats. The abdomen was cut opened and pylorus ligation was done without causing any damage to the blood supply. The stomach was replaced carefully, and the abdomen wall was closed in two layers with interrupted sutures. The animals were deprived of water during the 4 $\mathrm{h}$ post-operative period. ASP $(20 \mathrm{mg} / \mathrm{ml})$ was given for $4 \mathrm{~h}$ to the overnight fasted animals. After the experiment, the animals were sacrificed by an overdose of ether and the stomach was dissected out. Ulcer index (UI) in the above models was calculated by adding the number of ulcer per stomach plus the severity of ulcer converted as $1+$ (one plus) per stomach by a person unaware of the experimental protocol $[15,16]$. EtOH was given to the overnight fasted rats and they were sacrificed by an overdose of ether after $1 \mathrm{~h}$ of EtOH. Stomach was incised along the greater curvature and examined for ulcers. The UI was scored, based upon the product of length and width of the ulcers, present in the glandular portion of the stomach (mm2/rat) [17].

\section{Ulcer healing study}

Chronic GU was produced using 50\% acetic acid (AA). The rats were anaesthetized with pentobarbitone $(35 \mathrm{mg} / \mathrm{kg}$, i. p.). The abdomen was cut opened with an incision and the stomach was visualized. A cylindrical glass tube of $6 \mathrm{~mm}$ in diameter was tightly placed upon the anterior serosal surface of the glandular portion of stomach $1 \mathrm{~cm}$ away from the pyloric end. AA $(0.06 \mathrm{ml} / \mathrm{animal})$ was instilled into the tube and allowed to remain for $60 \mathrm{~s}$ on the gastric wall. After removal of the acid solution, the abdomen was closed in two layers and animals were caged and fed normally. The test drugs were given in their respective doses on day one, orally $4 \mathrm{~h}$ after the application of AA and continued either up to $7 \mathrm{~d}$ after induction of ulcer. The animals were then sacrificed after $18 \mathrm{~h}$ of the last dose of test/standard drugs on 8th day of an experiment to assess the ulcer size and healing. UI was calculated based upon the product of length and width $\left(\mathrm{mm}^{2} / \mathrm{rat}\right)$ of ulcers [18].

\section{Gastric secretion/mucosal studies in PL rats}

After $4 \mathrm{~h}$ of PL as described above, the stomachs were dissected out. The gastric juice was collected into a centrifuge tube through a nick along the greater curvature of the stomach and centrifuged for $5 \mathrm{~min}$ at $2000 \mathrm{rpm}$. The volume of the supernatant was expressed as $\mathrm{ml} / 100 \mathrm{~g}$ body weight. Free and total acidity [19] and peptic activity [20] were studied in the gastric juice while, mucosubstances like total hexoses [21], hexosamine [22], fucose [23], sialic acid [24] and protein [25]were estimated in the $90 \%$ ethanol precipitate of gastric juice using standard procedures and were compared with respect to the control CMC group [26]. The mucosal scrapings were also taken from the glandular portion of the stomach and were homogenized in phosphate buffered saline for the estimation of various fractions of glycoproteins, as mentioned above for mucosubstances [14, 27].

\section{Gastric mucosal studies of free radicals and antioxidants in CRS rats}

Protein (mg/g wet tissue) [25], free radicals, lipid peroxidation (LPO, MDA nmol/mg protein) [28] and nitric oxide (NO, nmol/mg protein) [29] and antioxidants, catalase (CAT, $\mathrm{mU} / \mathrm{mg}$ protein) [30] superoxide dismutase (SOD) [31], U/mg protein) and reduced glutathione (GSH, nmol/mg protein) [32] were estimated in the rat gastric mucosal homogenate of CMC (negative control), unrestraint stress (URS) and CRS alone or treated with oral CMC (control)/PGE (100 mg/kg, test drug)/positive controls, SCF (500 mg/kg)/OMZ (2 $\mathrm{mg} / \mathrm{kg}$ ). The doses of SCF and OMZ were selected on the basis of our previous antiulcer work [14].

\section{Stastical analysis}

Results are expressed as mean \pm SEM $(n=6)$. Data were analyzed by one-way ANOVA followed by Dunnett's test for multiple comparison and significance was declared at $P<0.05$.

\section{RESULTS}

\section{Gastric ulcer study}

\section{Antiulcer}

Graded doses of PGE (50, 100 and $200 \mathrm{mg} / \mathrm{kg})$, antisecretory, OMZ $(2.0 \mathrm{mg} / \mathrm{kg})$ and ulcer protective, SCF $(500 \mathrm{mg} / \mathrm{kg})$ were given orally, once daily for six days and a seventh dose was given on the day of experiment to $18 \mathrm{~h}$ fasted rats, one hour before the experiment to rats. PGE showed a dose-dependent decrease in ulcer index against CRS-induced GU (Control CMC UI-27.4 \pm 3.09 ; PGE-20.8 to $57.3 \%$ decrease, $\mathrm{P}<0.1$ to $\mathrm{P}<0.01$ ) compared with the control CMC group. PGE, $100 \mathrm{mg} / \mathrm{kg}$ showed optimal antiulcer effect $(46.0 \%$ decrease, $\mathrm{P}<0.01)$ and was comparable with both, OMZ $(65.7 \%$ decrease, $\mathrm{P}<0.001)$ and SCF $(61.7 \%$ decrease, $\mathrm{P}<0.001)$ so this dose was selected for further studies (fig. 1).

ASP-, PL-and EtOH-induced GU rats showed UI as 21.8 \pm 2.40 ; $15.0 \pm 2.91$ and $26.4 \pm 4.86 \mathrm{~mm}^{2} /$ rat respectively. PGE $(100 \mathrm{mg} / \mathrm{kg})$ showed a significant reduction (protection) in UI (50.5 to $79.7 \%$ protection, $\mathrm{P}<0.05$ to $\mathrm{P}<0.01$ ) against $\mathrm{ASP}-$, $\mathrm{PL}$-and EtOH-induced GU in rats. The ulcer protective effect of PGE was comparable with both OMZ ( 80.1 to $85.5 \%$ protection, $\mathrm{P}<0.01$ to $\mathrm{P}<0.001$ ) and SCF $(72.2$ to $75.7 \%$ protection, $\mathrm{P}<0.01$ to $\mathrm{P}<0.001$ ) (fig. 2). 


\section{Ulcer healing}

Ulcer healing effect of PGE was observed in AA-induced GU (CMC+AA UI-11.7 $\pm 1.61 \mathrm{~mm}^{2} / \mathrm{rat}$ ). PGE, OMZ and SCF showed 60.1 90.0 and $73.4 \%$ ulcer healing $(\mathrm{P}<0.001)$ compared with control CMC+AA group (fig. 1).

\section{Gastric secretion study}

\section{Acid pepsin secretion}

PGE showed little or no change in gastric juice volume, acid and pepsin secretion in terms of concentration (3.4 to $10.7 \%$ decrease) and output ( 4.2 to $11.0 \%$ decrease) compared with CMC control group. OMZ-treated rats showed a significant decrease in all the above parameters $(28.4$ to $59.9 \%$ decrease, $\mathrm{P}<0.05$ to $\mathrm{P}<0.001$ ) while, SCF showed a significant decrease in peptic concentration and output (23.4 to $28.7 \%, \mathrm{P}<0.05$ ) compared with $\mathrm{CMC}$ control group (table 1 ).

\section{Mucin secretion}

Mucoproteins in the gastric juice were expressed in terms of the ratio between total carbohydrates (TC, a sum of individual carbohydrates like total hexoses, hexosamine, fucose and sialic acid to protein (P) i.e. TC: $\mathrm{P}$ ratio which is regarded as a reliable index of mucin secretion. PGE-treated rat showed significant increase in the individual carbohydrate $(35.2$ to $98.1 \%$ increase, $\mathrm{P}<0.05$ to $\mathrm{P}<0.001)$ and TC $(41.5 \%, \mathrm{P}<0.01)$ and slight decrease in protein leading to significant increase in TC: $\mathrm{P}$ ratio $(55.1 \%$, $\mathrm{P}<0.05)$ compared with control CMC group. The above effect of PGE was comparable with SCF which also showed a significant effect on the above parameters. OMZ, on the other hand, was found to have no effect on mucin secretion (table 1).

\section{Gastric mucosal study}

\section{Glycoproteins}

Glycoproteins were also expressed in terms of TC: P ratio as mentioned for mucoproteins. PGE tended to increase or increased the individual carbohydrate $(17.6$ to $38.7 \%$ increase, $\mathrm{P}<0.1$ to $\mathrm{P}<0.05)$ and TC $(30.7 \%$, $\mathrm{P}<0.01$ ) and slight decrease in protein leading to significant increase in TC: $\mathrm{P}$ ratio $(35.7 \%, \mathrm{P}<0.05)$ compared with control $\mathrm{CMC}$ group. The above effect of PGE was comparable with SCF while, OMZ did not show any effect on them (table 1).

\section{Protein, free radicals and antioxidants}

Protein (mg/g wet tissue), free radicals, LPO (MDA nmol/mg protein) and NO (nmol/mg protein), and antioxidants, CAT (mU/mg protein), SOD (U/mg protein) and GSH (nmol/mg protein) were estimated in the gastric mucosal homogenate of CMC (negative control)-treated unrestraint stress (URS) and cold restraint stress (CRS, control) rats or rats treated with PGE+CRS (test extract) and/OMZ/SCF+PGE (positive controls).

\section{Protein content}

There was little or no change in the protein content of gastric mucosal homogenate of URS and CRS group and between CRS and PGE/OMZ/SCF+CRS groups (table 2).

\section{Free radicals}

Both LPO and NO were increased significantly when the rats were subjected to CRS (increase LPO-58.3\%, $\mathrm{P}<0.01$; NO-48.4\%, $\mathrm{P}<0.01$ ) when compared with URS rats (table 2). PGE like ulcer protective drugs, OMZ and SCF showed a significant decrease in their levels when compared with CRS group (38.8 to $45.1 \%$ decrease, $\mathrm{P}<0.01$ to $\mathrm{P}<0.001$ ) (table 2).

\section{Antioxidants}

Antioxidant enzymes SOD and CAT and non-enzyme reduced glutathione, GSH were estimated in the gastric mucosal homogenate of URS, CRS alone and in PGE-, OMZ-and SCF-treated CRS rats. SOD was increased $(21.8 \%, \mathrm{P}<0.01)$ while, both CAT and GSH were decreased significantly when the rats were subjected to CRS (decrease CAT-44.8\%, P<0.01; GSH-33.1\%, P<0.001) when compared with URS rats (table 2).

PGE showed a significant decrease in SOD level by $16.2 \%$ $(\mathrm{P}<0.01)$ and increase in CAT and GSH levels by $48.7(\mathrm{P}<0.01)$ and $43.8 \%(\mathrm{P}<0.001)$ respectively compared with CRS group.

OMZ-and SCF-treated CRS rats showed a decrease in SOD (7.9 to 9.3\%, $\mathrm{P}<0.05)$ but either tended to increase or increased CAT and GSH $(21.9$ to $30.3 \%, \mathrm{P}<0.1$ to $\mathrm{P}<0.01)$ compared with CRS alone (table 2).

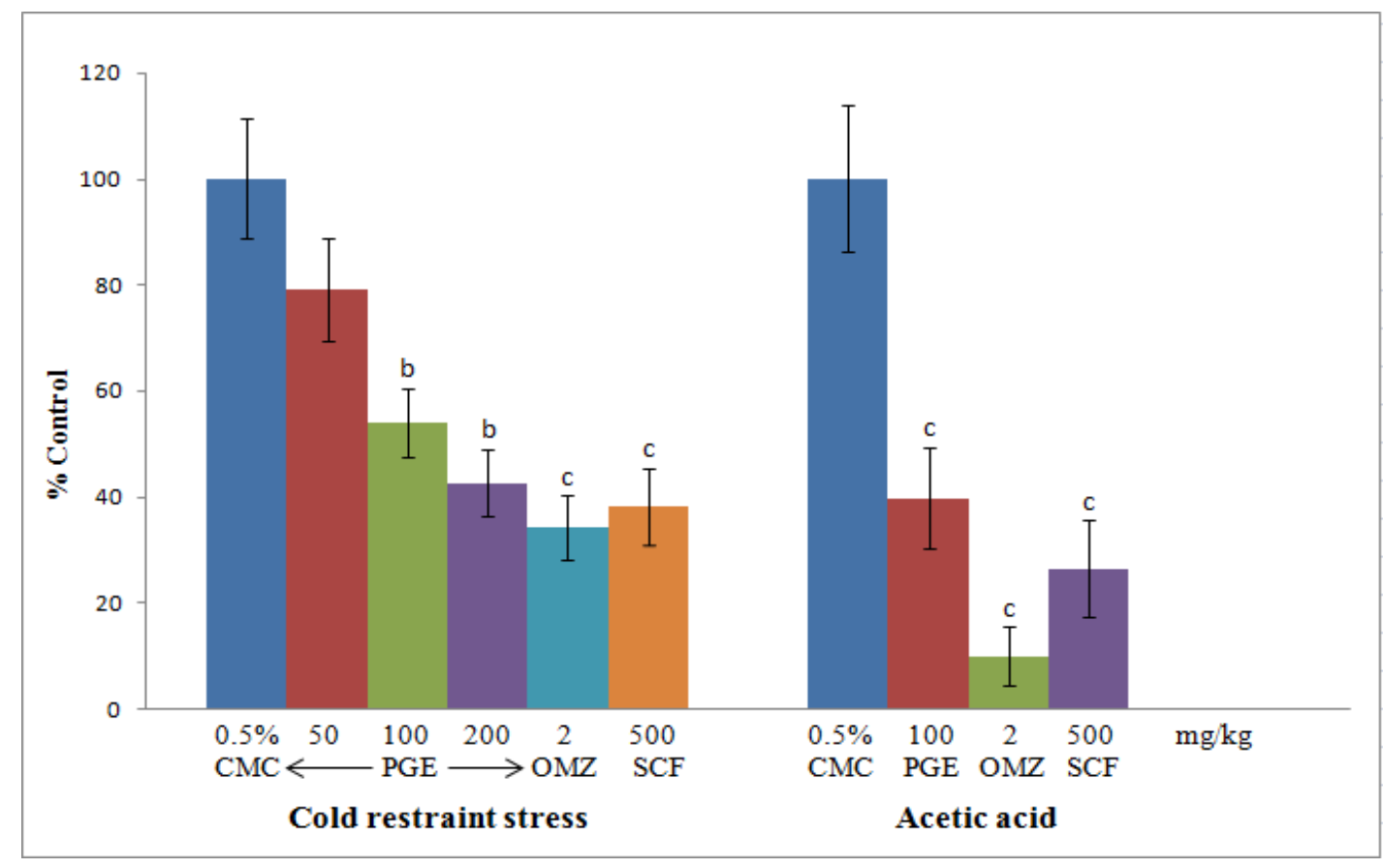

Fig. 1: Effect of PGE, OMZ and SCF on CRS-and AA-induced GU in rats ${ }^{\mathrm{b} P}<0.01$ and $\mathrm{CP}<0.001$ compared to respective $\mathrm{CMC}$ control 


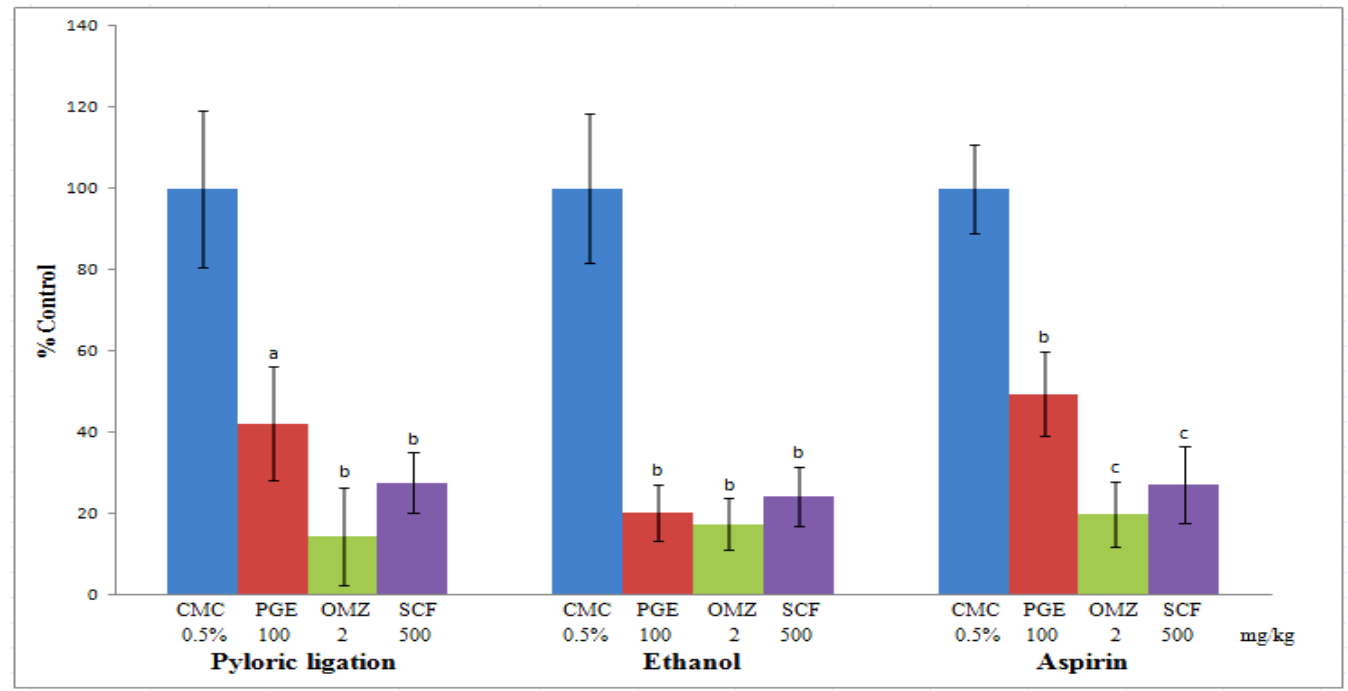

Fig. 2: Effect of PGE, OMZ and SCF on pylorus ligated-, ethanol-, and aspirin-induced GU, aP<0.05, $\mathrm{bP}<0.01$ and $\mathrm{cP}<0.001$ compared to respective control group

Table 1: Effect of PGE, OMZ and SCF on gastric acid, pepsin and mucin secretion and mucosal glycoproteins in PL-induced GU in rats

\begin{tabular}{|c|c|c|c|c|}
\hline Parameters (mg/kg) & CMC (0.5\%) & PGE (100) & OMZ (2) & SCF (500) \\
\hline \multicolumn{5}{|l|}{ Gastric Juice } \\
\hline \multicolumn{5}{|l|}{ Acid-pepsin } \\
\hline Volume (ml/100 g) & $1.90 \pm 0.15$ & $1.89 \pm 0.10$ & $1.36 \pm 0.11^{\mathrm{a}}$ & $1.77 \pm 0.09$ \\
\hline Acid conc. $(\mu \mathrm{Eq} / \mathrm{ml})$ & $89.3 \pm 6.99$ & $86.3 \pm 10.7$ & $50.1 \pm 3.25^{c}$ & $81.9 \pm 7.13$ \\
\hline Acid output ( $\mu \mathrm{Eq} / 4 \mathrm{hr})$ & $170.2 \pm 15.9$ & $163.1 \pm 18.2$ & $68.2 \pm 6.97 \mathrm{c}$ & $144.4 \pm 17.3$ \\
\hline Pepsin conc. $(\mu \mathrm{mol} / \mathrm{ml})$ & $207.7 \pm 19.0$ & $185.4 \pm 20.2$ & $147.2 \pm 9.67^{\mathrm{a}}$ & $159.2 \pm 14.9^{*}$ \\
\hline Pepsin output ( $\mu \mathrm{mol} / 4 \mathrm{hr})$ & $394.6 \pm 31.9$ & $351.2 \pm 34.7$ & $200.6 \pm 22.0^{c}$ & $281.4 \pm 18.7^{a}$ \\
\hline \multicolumn{5}{|l|}{$\operatorname{Mucin}(\mu \mathrm{g} / \mathrm{ml})$} \\
\hline Total hexoses & $259.6 \pm 24.8$ & $351.1 \pm 23.3^{\mathrm{a}}$ & $212.9 \pm 28.3$ & $332.7 \pm 17.9^{a}$ \\
\hline Hexosamine & $143.2 \pm 19.8$ & $208.1 \pm 22.9^{a}$ & $153.6 \pm 10.0$ & $216.2 \pm 17.3^{a}$ \\
\hline Fucose & $78.5 \pm 6.74$ & $107.0 \pm 7.13^{\mathrm{a}}$ & $77.0 \pm 2.01$ & $99.7 \pm 5.79^{a}$ \\
\hline Sialic acid & $25.9 \pm 4.11$ & $51.3 \pm 2.59^{c}$ & $25.1 \pm 1.97$ & $49.7 \pm 3.13^{c}$ \\
\hline Total carbohydrates (TC) & $507.2 \pm 30.0$ & $717.5 \pm 40.1^{\mathrm{b}}$ & $468.6 \pm 33.4$ & $698.3 \pm 29.7^{b}$ \\
\hline Protein (P) & $345.6 \pm 43.4$ & $314.3 \pm 43.4$ & $330.3 \pm 18.8$ & $293.7 \pm 11.7$ \\
\hline TC: P ratio & $1.47 \pm 0.18$ & $2.28 \pm 0.22^{\mathrm{a}}$ & $1.42 \pm 0.12$ & $2.38 \pm 0.25^{\mathrm{a}}$ \\
\hline \multicolumn{5}{|c|}{$\begin{array}{l}\text { Gastric Mucosa } \\
\text { glycoproteins }(\mu \mathrm{g} / 100 \mathrm{mg} \text { wet tissue) }\end{array}$} \\
\hline Total hexoses & $1880 \pm 208$ & $2608 \pm 193^{\mathrm{a}}$ & $1870 \pm 150$ & $2569 \pm 201^{\mathrm{a}}$ \\
\hline Hexosamine & $1196 \pm 91.4$ & $1407 \pm 70.4$ & $1092 \pm 78.3$ & $1397 \pm 93.7$ \\
\hline Fucose & $157.9 \pm 22.0$ & $209.4 \pm 19.2$ & $178.1 \pm 29.8$ & $203.7 \pm 17.9$ \\
\hline Sialic acid & $90.3 \pm 7.30$ & $121.1 \pm 10.2^{\mathrm{a}}$ & $99.1 \pm 9.20$ & $123.7 \pm 11.3^{\mathrm{a}}$ \\
\hline Total carbohydrates (TC) & $3324 \pm 252$ & $4345 \pm 231^{a}$ & $3239 \pm 203$ & $4294 \pm 216^{\mathrm{a}}$ \\
\hline Protein (P) & $5934 \pm 265$ & $5727 \pm 211$ & $6288 \pm 276$ & $5689 \pm 212$ \\
\hline TC: P ratio & $0.56 \pm 0.04$ & $0.76 \pm 0.07 \mathrm{a}$ & $0.52 \pm 0.05$ & $0.75 \pm 0.06^{\mathrm{a}}$ \\
\hline
\end{tabular}

Results are mean $\pm \operatorname{SEM}(\mathrm{n}=6),{ }^{*} \mathrm{P}<0.1, \mathrm{P}<0.05,{ }^{\mathrm{b}} \mathrm{P}<0.01$ and ${ }^{\mathrm{c}} \mathrm{P}<0.001$ compared with respective $\mathrm{CMC}$ group

Table 2: Effect of PGE, OMZ and SCF on wet gastric mucosal protein, free radicals, LPO and NO and antioxidants, CAT, SOD and GSH in CRSinduced GU rats

\begin{tabular}{|c|c|c|c|c|c|}
\hline Parameters & CMC +URS & CMC +CRS & PGE (100) +CRS & OMZ (2) +CRS & SCF (500) +CRS \\
\hline \multicolumn{6}{|l|}{ PROTEIN (PR) } \\
\hline $\mathrm{PR}$ (mg/g wet tissue) & $58.9 \pm 2.61$ & $60.3 \pm 2.56$ & $61.3 \pm 2.17$ & $64.7 \pm 2.73$ & $59.6 \pm 2.81$ \\
\hline \multicolumn{6}{|l|}{ FREE RADICALS } \\
\hline LPO (nmol/mg protein) & $3.45 \pm 0.25$ & $5.46 \pm 0.42^{\mathrm{b}}$ & $3.00 \pm 0.30^{z}$ & $3.57 \pm 0.39 y$ & $3.11 \pm 0.37 y$ \\
\hline NO (nmol/mg protein) & $4.48 \pm 0.23$ & $6.65 \pm 0.51^{b}$ & $4.07 \pm 0.30 y$ & $4.20 \pm 0.40^{y}$ & $3.86 \pm 0.36 y$ \\
\hline \multicolumn{6}{|l|}{ ANTIOXIDANTS } \\
\hline SOD (U/mg protein) & $1.24 \pm 0.06$ & $1.51 \pm .0 .03^{\mathrm{b}}$ & $1.31 \pm 0.05^{y}$ & $1.37 \pm 0.05^{x}$ & $1.39 \pm 0.04^{x}$ \\
\hline CAT (mU/mg protein) & $5.43 \pm 0.49$ & $3.00 \pm 0.26^{b}$ & $4.46 \pm 0.38 y$ & $3.91 \pm 0.29^{x}$ & $3.85 \pm 0.31^{*}$ \\
\hline GSH (nmol/mg protein) & $39.6 \pm 1.89$ & $26.5 \pm 1.47^{c}$ & $38.1 \pm 2.07^{z}$ & $33.0 \pm 1.33^{y}$ & $32.3 \pm 1.56^{x}$ \\
\hline
\end{tabular}

Results are mean \pm SEM $(n=6)$, ${ }^{b} P<0.01$ and ${ }^{c} \mathrm{P}<0.001$ compared with respective CMC+URS group and ${ }^{*} \mathrm{P}<0.1,{ }^{x} \mathrm{P}<0.05,{ }^{\mathrm{y}} \mathrm{P}<0.01$, and ${ }^{ } \mathrm{P}<0.001$ compared with respective $\mathrm{CMC}+\mathrm{CRS}$ group 


\section{DISCUSSION}

The peel, rind and seeds of PG fruit have been reported to have gastric ulcer protective effects against $\mathrm{EtOH}, \mathrm{HCl}+\mathrm{EtOH}$ and $\mathrm{PL}$-induced $\mathrm{GU}$ in rats. It was further, reported that the ulcer protective effect of PG peel could be due to a decrease in acid secretion and promotion of mucosal defensive factors like enhanced mucin secretion, adhered mucosal mucoproteins and antioxidant status [8-11]. However, Lai and associates have reported no role of acid-pepsin secretion in the ulcer protective effects of PG [12]. As the etiopathogenesis of gastric ulcer is complex involving both offensive and defensive mucosal factors, so the present work was conducted using both acute and chronic GU models and estimation of offensive and defensive biochemical paradigms inappropriate GU rat models [14].

The cause of acute ulceration varies in different experimental models. Stress-induced ulcer are caused by an increase in gastric motility, vagal overactivity, mast cell degranulation, decreased gastric mucosal blood flow, diminished antioxidant system, increased free radicals and decreased PG synthesis leading to increase in acid secretion and back diffusion of $\mathrm{H}^{+}$ions and breaking up of the mucosal barrier. In the stomach, prostaglandins play a vital protective role, stimulating the secretion of bicarbonate and mucus, maintaining mucosal blood flow, and regulating mucosal cell turnover and repair and the suppression of prostaglandin synthesis by NSAIDs result in increased susceptibility to mucosal injury and gastroduodenal ulceration $[1,33]$.

Disturbances in mucosal blood flow, prostaglandins, gastric secretion, damage to the gastric mucosa, alterations in permeability, gastric mucus depletion and free-radical production are observed after the administration of ethanol [34]. PL-induced GU is caused by enhanced acid-pepsin secretion and breaks down of the gastric mucosal barrier [14]. AA-induced GU in the rat was reported to have close resemblance with clinical ulcers in location, chronicity and severity and serves as the most reliable model to study ulcer healing process. Chronic ulcers by AA are due to increase in the volume of acid output leading to subsequent pyloric obstruction and mucosal necrosis [35].

In our present study, PGE was found to protect the incidence and severity of GU induced by both physical (CRS and PL) and chemical agents (ASP and EtOH) and healed the chronic ulcer induced by AA indicating thereby that both offensive and defensive gastric mucosal factors are involved in its ulcer protective and healing effects. PL rat GU model is the best suitable model for studying the effects of a drug on offensive acid-pepsin secretion and defensive mucin secretion and mucosal glycoproteins [27]. Mucin is secreted by the mucus neck cells and coats the gastric mucosa, thereby preventing physical damage and back diffusion of hydrogen ions. Both mucin and mucus content of the mucosal cells i.e. glycoproteins were estimated in terms of TC: P ratio which is a reliable marker for them [36]. In our present study, PL rats treated with PGE showed no change in juice volume acid and peptic concentration and output, but it increased mucin secretion and mucosal glycoprotein content. The increase in mucus is important for the repair of superficial damage to the mucosa by forming a protective coat, and this mucoid cap provides a suitable microenvironment for repair by the process of restitution, a process of repair involving migration of viable surface mucosal cells to cover the damaged mucosa [1, 37]. Thus, our study is in conformity with other workers who reported that the ulcer protective effects of PG peel may be through increased secretion of mucin and mucosal glycoproteins $[10,12]$.

Oxidative damage is considered to be an important factor in the pathogenesis of ulcers as evidenced in different experimental and clinical models. Free radicals damage cellular membranes by releasing intracellular components like lysosomal enzymes and the free radical, particularly hydroxyl causes degeneration of hyaluronic acid, the principal component of the epithelial basement membrane, and thus promotes mucosal damage [38]. Free radicals also promote lipid peroxidation and membrane damage by cross-linking proteins, lipids and nucleic acids [39]. Lipid peroxidation caused by $\mathrm{OH}$, is increased in gastric lesions induced by ethanol, indomethacin, ischemia-reperfusion, water immersion and burn shock [33]. Nitric oxide plays an important role in the regulation of various cellular functions in cardiovascular, neuronal and immune systems. In the stomach, NO produced by constitutive NOS (cNOS) is considered to be beneficial in maintaining the mucosal integrity [40]. However, studies showed that NO produced from inducible NOS (iNOS) is involved in the inflammatory disorders like ulcerative colitis or intestinal lesions caused by NSAIDs and suggest that NO may play a detrimental role in such diseases [41]. Our study also indicated an increase in free radicals, LPO and NO level in CRS rats with enhanced gastric ulceration and their decrease was associated with ulcer protective and healing effects.

Antioxidant enzymes like SOD, CAT and GSH control ROS accumulation, and any imbalance in the activity of these antioxidants normally leads to faulty disposal of free radicals and their accumulation. Hydrogen peroxide may be reduced by enzymes glutathione peroxidase, but alternatively may react again with superoxide anion to form free hydroxyl radicals, which have a greater toxicity and a longer half-life than superoxide anion [39]. Stress-induced gastric ulceration, which is associated with increased lipid peroxidation and depletion of endogenous GSH is due to increased formation of $\mathrm{O}_{2} \cdots$, activation of SOD and inactivation of gastric peroxidase (GPO)-, a condition suitable for generation of $\mathrm{H}_{2} \mathrm{O}_{2}$ and formation of more reactive $\mathrm{OH}$, which causes antioxidant depletion and lipid peroxidation [33]. SOD and CAT play an important role in the detoxification of superoxide anion and $\mathrm{H}_{2} \mathrm{O}_{2}$ respectively; thereby protecting the cells against free radicalsinduced damage. SOD converts the reactive superoxide radical to $\mathrm{H}_{2} \mathrm{O}_{2}$, which if not scavenged by CAT can by itself cause lipid peroxidation by the generation of hydroxyl radicals [42].

The oxidative stress is caused due to an imbalance between the damaging free radicals and protective antioxidants. Our present study indicated an increase in the gastric mucosal LPO, NO and SOD and decreased in CAT and GSH in CRS rats. The rise in SOD could be due to induction of this enzyme to cope with the enhancing free radicals and decrease in CAT and GSH indicated their excessive utilization to neutralize free radicals [40]. PGE-treated CRS rats also showed reversal of the above parameters indicating decrease in the tissue damage and better repair and healing. Both ulcer protective and healing drugs, OMZ and SCF also reversed the rise in free radicals and SOD and decrease in CAT and GSH indicating the role of oxidative stress in ulcer damage. Our work on oxidative stress corroborates with the findings of another worker who have reported the role of antioxidants in the protective effects of PG fruits [7].

Many bioactive phytochemicals like polyphenols, flavonoids, tannins, etc. are reported in PG peel having antioxidant, anti-inflammatory and ulcer protective and healing effects $[12,13]$. The ulcer protective and healing effects of PGE could be due to the presence of these active principles. The ulcer protective effects of PGE are in conformity with that of Lai and associates who have shown no role of acid-pepsin secretion in ulcer protective effects of PG tannins [12]. Further, work on the inflammatory markers, cytokines and myeloperoxidase and vascular endothelial growth factor is under progress as they have been reported to play a role in ulcer diathesis.

\section{CONCLUSION}

This study provides evidence that the peel extract of Punica granatum have gastric cytoprotective effects through enhancement of defensive mucin secretion and glycoproteins and decrease in oxidative stress mainly through promoting antioxidant status. The present work does substantiate the folk medicinal use of this plant in peptic ulcer diseases.

\section{ACKNOWLEDGMENT}

Authors gratefully acknowledge the financial support provided by the Faculty of Medicine, Institute of Medical Sciences, Banaras Hindu University, Varanasi, 221005, India.

\section{CONFLICT OF INTERESTS}

Authors declare that they have no conflict of interest

\section{REFERENCES}

1. Goel RK, Bhattacharya SK. Gastroduodenal mucosal defence and mucosal protective agents. Indian J Exp Biol 1991;29:701-14. 
2. Patil VP, Viswanathswamy AHM, Kamblekar YJ, Hallikeri CS, Hatapakki BC. Gastroprotective and anti-ulcer properties of clozapine in pylorus ligated rats. Int J Pharmacol Biol Sci 2008;2:121-7.

3. Mohan Kumar M, Joshi MC, Prabha T, Dorababu M, Goel RK. Effect of plantain banana on gastric ulceration in NIDDM rats: the role of mucosal glycoproteins, cell proliferation, antioxidants and free radical. Indian J Exp Biol 2006;44:292-9.

4. Mózsik G. Gastric cytoprotection 30 y after its discovery by André Robert: a personal perspective. Inflammopharmacology 2010;18:209-21.

5. Rosa S, D'Souza D, Dhume VG. Gastric cytoprotection. Indian J Physiol Pharmacol 1991;35:88-98.

6. Garachh D, Patel A, Chakraborty M, Kamath JV. Phytochemical and pharmacological profile of Punica granatum. Int Res J Pharm 2012;3:65-8.

7. Bhandari PR. Pomegranate (Punica granatum L). Ancient seeds for modern cure? Review of potential therapeutic applications. Int J Nutr Pharmacol Neurol Dis 2012;2:171-84.

8. Alam MS, Alam MA, Ahmad S, Nazmi AK, Asif M, Jahangir T. Protective effects of Punica granatum in experimentallyinduced gastric ulcers. Toxicol Mech Methods 2010;20:572-8.

9. Gautam R, Sharma SC. Anti-ulcer activity of Punica granatum Linn in diabetic rats. Int J Pharm Pharm Sci 2012;4(Suppl 3):459-61.

10. Moghaddam G, Sharifzadeh M, Hassanzadeh G, Khanavi M, Hazimahmoodi M. Antiulcerogenic activity of the pomegranate peel (Punica granatum) methanol extract. Food Nutr Sci 2013;4:1-7.

11. Bakhtaoui Fatima-Zahra, Lakmichi H, Chait A, Gadhi CA. In vivo gastroprotective effects of five Moroccan Medicinal plants against gastric ulcer. Am J Phytomed Clin Ther 2014;2:1262-76.

12. Lai S, Zhou Q, Zhang Y, Shang J, Yu T. Effects of pomegranate tannins on experimental gastric damages. Zhongguo Zhong Yao Zazhi 2009:34:1290-4.

13. Haque N, Sofi G, Ali W, Rashid M, Itrat MA. Comparative review of phytochemical and pharmacological profile of Anar (Punica granatum Linn): a heaven's fruit. J Ayu Herb Med 2015;1:22-6.

14. Prabha T, Dorababu M, Goel Shalini, Agarwal PK, Singh A, Joshi VK, Goel RK. Effect of methanolic extract of Pongamia pinnata Linn seed on gastroduodenal ulceration and mucosal offensive and defensive factors in rats. Indian J Exp Biol 2009;47:649-59.

15. Sanyal AK., Pandey BL, Goel RK. The effect of a traditional preparation of copper, tamrabhasma, on experimental ulcers and gastric secretion. J Ethnopharmacol 1982;5:79-89.

16. Goel RK, Govinda Das D, Sanyal AK. Effect of vegetable banana powder on changes induced by ulcerogenic agents on dissolved mucosubstances in gastric juice. Indian J Gastroenterol 1985;4:249-51.

17. Hollander D, Tarnawski A, Kruse WJ, Gergley H. Protective effect of sucralfate against alcohol-induced gastric mucosal injury in the rat. Gastroenterol 1985;88:366-74.

18. Goel RK, Maiti RN. Gastric ulcer protective effect of Tamrabhasma an Indian Ayurvedic preparation of copper and plantain banana. Proceedings of First International Symposium on Natural Drugs and the Digestive tract, Naples Italy; 1992. p. 73-6.

19. Sanyal AK, Debnath PK, Bhattacharya SK, Gode KD. The effect of cyproheptadine on gastric activity. An experimental study. In: Pfeiffer CJ editor. Peptic Ulcer, Munksgaard, Copenhagen; 1971. p. 312-8.

20. Debnath PK, Gode KD, Govinda Das D, Sanyal AK. Effect of propranolol on gastric secretion in albino rats. Br J Pharmacol 1974;51:213-6

21. Winzler RJ. Determination of serum glycoproteins. Methods Biochem Anal 1958;2:279-311.

22. Dische Z, Borenfreund e. a spectroscopic method for the micro determination of hexosamine. J Biol Chem 1950;184:517-22.

23. Dische Z, Shettles LB. A specific colour reaction for methyl pentoses and spectrophotometric micro method for their determination. J Biol Chem 1948;175:595-603.
24. Warren L. The thiobarbituric acid assay of sialic acid. J Biol Chem 1959;234:1971-5.

25. Lowry OH, Rosebrough NJ, Farr AL, Randall RJ. Protein measurement with folin phenol reagent. J Biol Chem 1951;193:265-75

26. Sanyal AK, Mitra PK, Goel RK. A modified method to estimate dissolved mucosubstances in gastric juice. Indian J Exp Biol 1983;21:78-80.

27. Goel RK, Gupta Saroj, Shankar R, Sanyal AK. Anti-ulcerogenic effect of banana powder Musa sapientum var. paradisiaca) and its effects on mucosal resistance. J Ethnopharmacol 1986;18:33-44

28. Okhawa H Ohishi N, Yagi K. Assay for lipid peroxides in animal tissue by thiobarbituric acid reaction. Anal Biochem 1979;95:351-8

29. Miranda KM, Espey MG, Wink DA. A rapid, simple spectrophotometric method for simultaneous detection of nitrate and nitrite. Nitric Oxide 2001;5:62-71.

30. Aebi H. Catalase. In: Bergmeyer HU. editor. Methods in enzymatic analysis. Vol. 3 (2nd Ed.) New York: Academic Press; 1974. p. 673-7.

31. Kakkar P, Das B, Viswanathan PN. A modified spectrophotometric assay of superoxide dismutase. Indian J Biochem Biophys 1984;21:130-2.

32. Sedlak J, Lindsay RH. Estimation of total, protein-bound and non-protein sulfhydryl groups in tissue with Ellman's reagent. Anal Biochem 1968;25:192-205.

33. Bandyopadhyay D, Chattopadhyay A. Reactive oxygen speciesinduced gastric ulceration: protection by melatonin. Curr Med Chem 2006;13:1187-202.

34. Goel RK, Tavares IA, Bennett A. Effect of ethanol on eicosanoid synthesis by human gastric and colonic mucosal pieces. $\mathrm{Br} \mathrm{J}$ Pharmacol 1990;99:289-92.

35. Okabe S, Amagase K. An overview of acetic acid ulcer modelsthe history and state of the art of peptic ulcer research. Biol Pharm Bull 2005;28:1321-41.

36. Goel RK, Maiti RN, Mukhopadhyaya K. Effect of Tamrabhasma, an indigenous Indian preparation of copper, on rat gastric mucosal resistance. Indian J Exp Biol 1994;32:559-61.

37. Wallace JL. Increased resistance of the rat gastric mucosa to hemorrhagic damage after exposure to an irritant: the role of the "mucoid cap" and prostaglandin synthesis. Gastroenterology 1988;94:22-32.

38. Fridovich I. Biological effects of superoxide radical. Arch Biochem Biophys 1986;247:1-11

39. Del Maestro R, Thaw HH, Bjork J, Planker M, Arfors KE. Free radicals as mediators of tissue injury. Acta Physiol Scand 1980;Suppl 492:43-57.

40. Lopez-Belmonte J, Whittle BJR. The involvement of endothelial dysfunction, nitric oxide and prostanoids in the rat gastric microcirculatory responses to endothelin-1. Br J Pharmacol 1994:112:267-71.

41. Mourelle M, Vilaseca J, Guarner F, Salas A, Malagelada JR. Toxic dilation of the colon in a rat model of colitis is linked to an inducible form of nitric oxide synthase. Am J Physiol 1996;270:G425-30

42. Kumaraguruparan R, Subapriya R, Viswanathan P, Nagini $S$. Tissue lipid peroxidation and antioxidant status in patients with adenocarcinoma of the breast. Clin Chim Acta 2002;325:165-70.

\section{How to cite this article}

- Indal Chauhan, Ankita Sharma, Mayank Gangwar, Manish Kumar Gautam, Amit Singh, Raj Kumar Goel. Gastric antiulcer and ulcer healing effects of Punica granatum L. peel extract in rats: the role of offensive and defensive mucosal factors and oxidative stress. Int J Pharm Pharm Sci 2017;9(5):6-11. 